\title{
A MULTI-AGENT MICROGRID ENERGY MANAGEMENT SOLUTION FOR AIR TRANSPORT ELECTRIFICATION Zekun Guo ${ }^{1}$, Xin Zhang ${ }^{1 *}$, Rui Zhang ${ }^{2}$
}

\author{
${ }^{1}$ Department of Electronic and Electrical Engineering, Brunel University London, Uxbridge, United Kingdom \\ ${ }^{2}$ Electricity National Control Centre, National Grid ESO, Wokingham, United Kingdom \\ *xin.zhang@brunel.ac.uk
}

Keywords: AIR TRANSPORT, ELECTRIFICATION, MICROGRID, CHARGING, RENEWABLE ENERGY

\begin{abstract}
To achieve net-zero emissions in air transport industry with defined CO2 mitigation objectives in "Flightpath 2050", electrically powered aircraft as part of electrified aviation become attractive technologies. In recent years, many electric aircraft prototypes for short-haul commuting air transport have been designed. Most of them are supposed to be deployed in the real airports by $2030-2035$. However, the ground power systems and associated electric aircraft charging operation are also essential for realising electrified aviation. Moreover, various renewable generation technologies in terms of PVs and micro wind turbines, electric vehicles and energy storage systems are expected to be integrated into the airport to form a decarbonised microgrid energy system. Therefore, there is a challenge of designing airport microgrids associated with energy scheduling algorithms for electric aircraft charging as well as airport decarbonisation. To overcome this challenge, this paper proposes a multi-agent real-time microgrid energy scheduling solution for electrified air transport. The coordination algorithm between the electric aircraft charging system and the electric vehicles charging in the airport parking lot is developed to enhance the resilience and operational flexibility of the airport microgrid. The stochastic behaviours of the airport passengers and renewable power generation are integrated into the airport microgrid energy management solution. The study shows that the airport microgrid can achieve the resilience through the proposed energy management solution.
\end{abstract}

\section{Introduction}

The civil aviation develops substantially over the past decades and contributes to around $2 \%$ of the global greenhouse gas emission. To limit or reduce the aviationrelated climate impact, alternative power source aircraft technology and the more efficient energy infrastructure become necessary measures. An increasing number of aircraft designers are working on the electric propulsion system for electric aircraft (EA) [1].

The pure-electric commercial aircraft requires large energy density batteries in a range of at least $1,000 \mathrm{Wh} / \mathrm{kg}$ [2]. Under the fact that the battery energy density may not improve at the desired rate, the adoption of short-haul commuting electric aircraft would come into reality in the near term [3].

While the aircraft designers and aerospace engineers are pushing the boundary of the electric propulsion system, little research has been focusing on the energy infrastructure to support the future air transport electrification. One of the compulsory infrastructure for EA is the high-power EA charging system [4]. The traditional airport consumes a large amount of electricity but it is not designed for additional energy that is required to serve the novel EA. The additional charging infrastructure for EA will bring power quality and operation issues (e.g. power balance, voltage control) to the ground electrical power systems. At the same time, more distributed energy resources are required to integrate into air transport electrification to achieve the decarbonisation objectives such as net-zero emissions.

The electric vehicles (EVs) parking at the airport is another important and potential $\mathrm{V} 2 \mathrm{G}$ source in the airport that has not been exploited [5]. Both the airport parking lot EV and the airport EA have distinct characteristics that make them as a dispatchable energy source for microgrid energy management as well as the interactions with the power grid. For example, because the airport EVs and EA are highly scheduled based on the pre-booked air travelling patterns, the power consumption of the EVs and EA charging system is predictable with little uncertainty. The target leaving time of airport parking lot EV that belongs to the air passengers could be pre-set according to their travel plans. The airport operators are able to centrally manage this information to schedule and dispatch both airport EVs and EA for airport microgrid energy management. However, the challenges associated with airport parking lot EVs to provide V2G service include:

- Linking the airport EV parking behaviours with the EA flight schedules.

- Real-time management of the state of charge (SoC) of airport EVs to both comfort the passengers' travel target and support the airport microgrid operation.

The future microgrid energy system for the airport will adopt large-scale distributed energy resources (DERs) [6]. The DERs such as PVs and wind turbines (WTs) are proposed to 
supply clean energy to the airport energy infrastructure. The DERs can also help to improve the reliability and resilience of airport microgrid operation.

This article proposes a multi-agent real-time microgrid energy management solution for electrified air transport. A distributed and coordinated control charging strategy for long-term and short-term airport parking EVs is developed. The V2G service of the airport parking EV that can support the microgrid energy management is quantified.

\section{Airport Microgrid Architecture}

When the charging infrastructure for supporting airport EA and EV is adopted in future airports, the energy consumption will be significantly increased. Such energy supply gap needs to be filled with high penetration of DER. An airport microgrid system is proposed to manage the EA and EV charging load, PV, Energy storage system (ESS), and wind turbines (WT) as shown in Fig. 1.

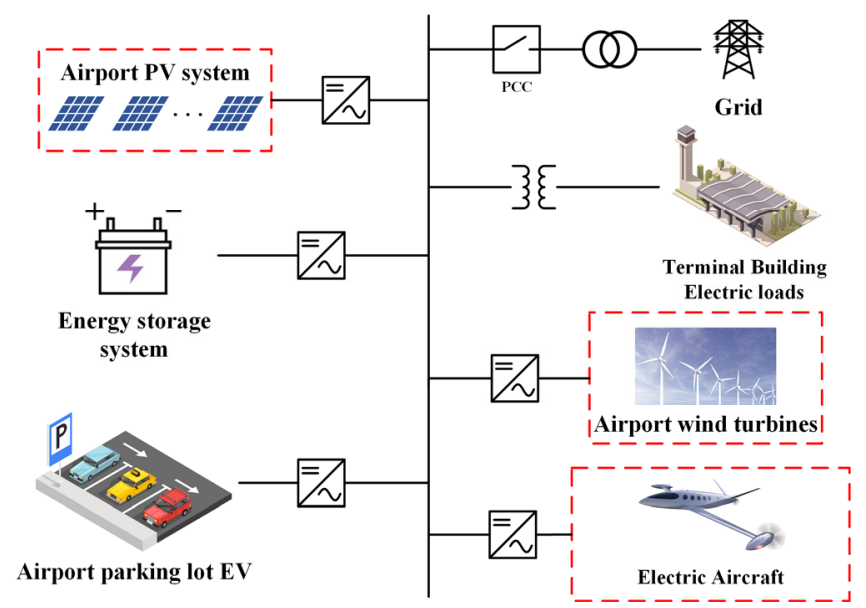

Fig. 1 Airport Microgrid architecture

\subsection{Electric aircraft scheduling}

The "Eviation Alice", which is shown in Fig. 2, is considered as a reference electric aircraft, its technical characteristics of which are shown in Table 1. The designed travel distance range of aircraft is suitable for domestic commuting flights. This aircraft is expected to be adopted in airports by 2024 [7].

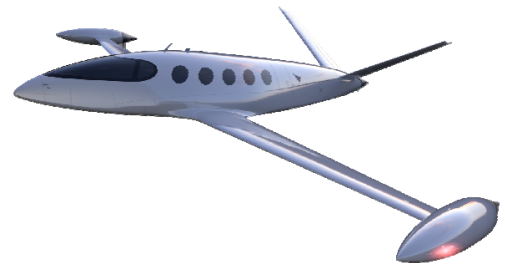

Fig. 2 "Eviation Alice" aircraft [7]

Conventionally, most commuter aircraft can transport 20-50 passengers, with a distance range of less than $1000 \mathrm{~km}$. The "Eviation Alice" will be used to replace conventional commuter aircraft such as SF3 (Saab 340B), as shown in Table 1. As the passenger capacity of SF3 is four times higher than the Eviation Alice, it is assumed that four EAs will be utilised to conduct one existing commuter flight mission. To avoid a simultaneous high-power EA charging on the airport microgrid, the flight is rescheduled to evenly distribute one conventional aircraft into four electric aircraft, as shown in Fig. 3. The constraint is that the rescheduled EA arrival time should be within 2 hours' range from the original arrival time.

Table 1 The characteristics of electric aircraft and conventional aircraft

\begin{tabular}{lll}
\hline Design property & Eviation Alice & SF3 \\
\hline Passenger & $9(+2$ crew $)$ & 36 \\
Distance Range $(\mathrm{nm})$ & 440 & 977 \\
Battery Energy (kWh) & 900 & - \\
Rated charging power (MW) & 0.3 & - \\
Fast charging power (MW) & 1.26 & - \\
Charging/discharging efficiency & $95 \%$ & - \\
\hline
\end{tabular}

The objective function is to minimise the peak to average ratio (PAR) of the EA charging power, as Eq. (1). The optimised rescheduling process is based on Monte Carlo simulation running 20,000 steps.

$$
P A R=\frac{\operatorname{Max}\left(P_{\text {load }, t}\right)}{\operatorname{Average}\left(P_{\text {load }, t}\right)}
$$

Where, $P_{\text {load,t }}$ is the load power of EA charging.

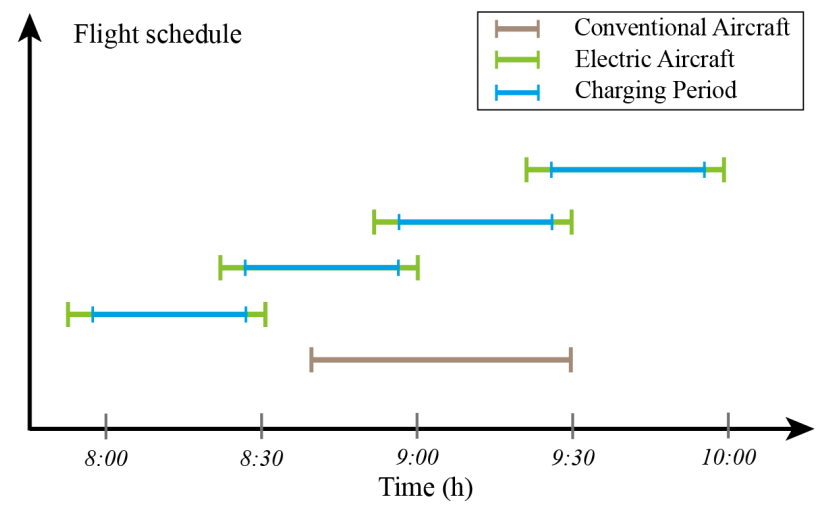

Fig. 3 Re-scheduling for electric aircraft charging

\subsection{Electric vehicles scheduling}

Most of the UK airports have separate parking lots for shortterm and long-term EV parking. In this work, passengers who travel back within 5 to 24 hours are defined as short-term parking passengers, those who come back in longer than 24 hours are long-term parking passengers. Usually, the parking passengers tend to book to-and-from tickets, therefore the EVs in airport parking lots will be pre-booked in advance with a certain return date which can be linked to the flight scheduling.

The EVs owned by airport employees who drive to work are also considered. The number of airport employees can be calculated using an approximate median value of 0.57 employees per thousand passengers per annum [8]. In Luton 
Airport, there are $46 \%$ of the passengers decided to travel to the airport by their private cars. In order to reduce the congestion of airport parking lots, the airport operators tend to limit the employers who travel to and from work by cars to $60 \%$ [9].

The daily EV scheduling in airport parking lot is correlated to the passenger travel plan and flight arrival and departure schedules, which can be modelled as a stochastic process.

\section{Airport Microgrid Modelling Methodology}

The power balance in the microgrid system can be calculated by the demand and generation at the point of common coupling (PCC), whether import/export power from/to the main grid determines whether the power balance is positive or negative.

$$
\begin{aligned}
& P_{\text {balance }, t}=\left(P_{W T, t}+P_{P V, t}+P_{V 2 G, t}+P_{B 2 G, t}\right) \\
& -\left(P_{G 2 V, t}+P_{G 2 B, t}+P_{E A, t}+P_{T B, t}\right)
\end{aligned}
$$

Where $P_{W T, t}, P_{P V, t}, P_{V 2 G, t}$ and $P_{B 2 G, t}$ represent the power generation from wind, solar, EV discharge, and battery energy storage system (BESS) discharge respectively. $P_{G 2 V, t}$, $P_{G 2 B, t}, P_{G 2 A, t}$ and $P_{T B, t}$ represent charging demand of $\mathrm{EV}$, BESS and EA, and the terminal building power demand.

The airport microgrid is modelled as a multi-agent based energy system as follows.

\subsection{Air passenger agent}

To-and-from passengers are assumed to book tickets according to random distributions. Firstly, the desired return days and hours are selected according to the uniform distribution, then the closest flight that has an available ticket is booked. The proportion of passengers who drive to the airport and book to-and-from tickets are assumed to be $30 \%$ and $50 \%$ respectively. In addition, $10 \%$ of the driving passengers are assumed to use long-term parking. Airport employees commute to and from work are according to a proposed work schedule. The on and off duty times are $6 \mathrm{am}$ and $8 \mathrm{pm}$ respectively. The arrival in advance time is assumed to be random uniformly from 10 minutes to 60 minutes. When the drivers arrive at the airport and park their EVs, the target departure time of the EVs will be set. When the passengers return to the airport and the employees are getting off the work, they will send a "leave" request to their EVs.

\subsection{Renewable generation agent}

The renewable power generation units include PVs, WTs, and an ESS. Each distributed power generation unit is modelled as an agent.

\subsubsection{Photovoltaics modelling}

The airport building area can be used to install PVs. In this paper, the following model is used to calculate the generation output of PVs. The PV agent is based on the model developed by [10].

$$
P_{P V, t}=\mathrm{IT} \times \eta \times A_{P V}
$$

Where IT is the total solar radiation incident on the surface of $\mathrm{PV}, \mathrm{kWh} / \mathrm{m}^{2} . \eta$ is the efficiency of the solar PV system, and is assumed to be 0.8. $A_{P V}$ is the area of the PV system $\left(\mathrm{m}^{2}\right)$.

\subsubsection{Energy storage system modelling}

A lithium-ion battery ESS is adopted for the airport microgrid. The following equations are modelled as a system dynamic model:

$$
\begin{gathered}
E_{t}^{E S}=E_{t-1}^{E S}+\eta_{b a t, c} P_{c, t}^{E S}-\eta_{b a t, d} P_{d, t}^{E S} \\
P_{c, t}^{E S}, P_{d, t}^{E S} \leq P_{\text {Max }}^{E S}
\end{gathered}
$$

Where, $E_{t}^{E S}$ is the battery energy at time t, $\eta_{b a t, c}$ and $\eta_{b a t, d}$ are charging and discharging efficiency of the ESS, $P_{c, t}^{E S}$ and $P_{d, t}^{E S}$ are charging and discharging power of the ESS, and they are less than the maximum battery charger power.

\subsubsection{Wind turbine modelling}

Wind turbines are not widely applicable in airports as they have a physical conflict with airspace activities, which may result in potential hazards to the low-flying aircraft. However, a few airports have successfully installed $30-50 \mathrm{~m}$ wind turbines in long distances to the runways, these projects are following airspace safety restrictions [11]. In this paper, a 45metre-tall WT (Enercon E44 900) is chosen for renewable generation in the airport. The turbine has a cut-in speed of 3 $\mathrm{m} / \mathrm{s}$, a cut-out speed of $25 \mathrm{~m} / \mathrm{s}$, re-cut-in speed of $13 \mathrm{~m} / \mathrm{s}$, with a rated power of $900 \mathrm{~kW}$ [12].

Based on the model developed in [10]. The output of the wind generation depends on the wind speed and the characteristics of the WT. The factors include cut-in velocity $V_{W T, c i}$, cut-out velocity $V_{W T, c o}$, and the rated velocity $V_{W T \text {,rated }}$.

$$
P_{W T, t}\left(V_{W T, t}\right)= \begin{cases}0 & , 0 \leq V_{W T, t} \leq V_{W T, c i} \\ a V_{W T, t}^{3}-b P_{W T, \text { rated }} & , V_{W T, c i} \leq V_{W T, t} \leq V_{W T, \text { rated }} \\ P_{W T \text {,rated }} & , V_{W T \text { rated }} \leq V_{W T, t} \leq V_{W T, c o} \\ 0 & , V_{W T, t} \geq V_{W T, c o}\end{cases}
$$

Where:

$$
\begin{aligned}
& a=\frac{P_{W T, \text { rated }}}{\left(V_{W T, \text { rated }}^{3}-V_{W T, c i}^{3}\right)} \\
& b=\frac{V_{W T, c i}^{3}}{\left(V_{W T, \text { rated }}^{3}-V_{W T, c i}^{3}\right)}
\end{aligned}
$$

Where, $P_{W T, t}$ is the power generation output of the wind turbine, $P_{W T, \text { rated }}$ is the rated power of the wind turbine.

\subsection{Electric Aircraft agent}

The aircraft agent is an event-based model, there are four events for an EA: arrival, start charge, fully charged, and 
departure. The aircraft is assumed to start charging 10 minutes after arrival and finish charging within 30 minutes. To avoid the charging process caused flight mission delays, the fast charger that has a rated power of $1.8 \mathrm{MW}$ is adopted, the charging load is modelled as Eq. (9). The passengers' information is recorded in a collection of the aircraft agent. The initial SOC of arrival EA is assumed to be 0.2 .

$$
P_{E A, t}=P_{E A}^{\text {rated }} \cdot N_{c, t}
$$

Where, $P_{E A}^{\text {rated }}$ is the rated power of the EA fast charger, $N_{c, t}$ is the number of charging EA at time t.

\subsection{EV agent in parking lot}

The parking lot EV agent simulates a population of EVs. The EV agent starts when the passengers and employees who drive to the airport parking lot. The EV target leaving time is set according to the EV owner. The EV battery energy and rated charging power are assumed to be $100 \mathrm{kWh}$ and 100 $\mathrm{kW}$ respectively. The EV initial state of charge (SoC) on arrival is assumed to vary uniformly between $50 \%$ to $80 \%$. The following steps describe the travel pattern of airport parking EVs, also as shown in Fig. 4.

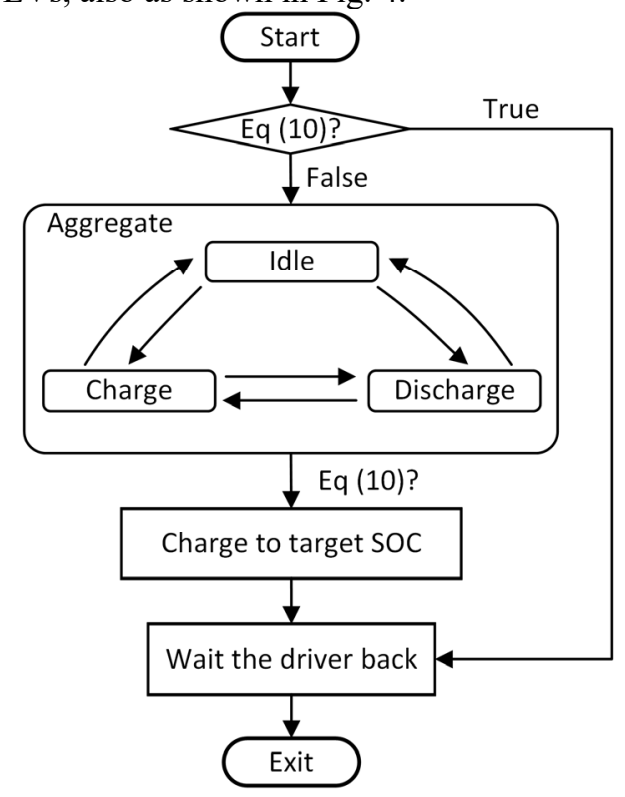

Fig. 4 The state flow behaviours of parking lot EV agents

Step 1: When the driver (passenger or employee) arrives at the airport parking lot, the EV agent will be at the "Parking" state. Then the agent will decide whether this EV is able to connect in the aggregator based on the formula Eq. (10).

$$
S O C_{t}^{E V}+\eta_{E V, c} P_{c, t}^{E V}\left(T_{\text {Target }}-20-t\right) / E^{E V} \leq S O C_{\text {Target }}^{E V}
$$

Where, $S O C_{t}^{E V}$ is the SOC of EV at time $t, \eta_{E V, c}$ is the charging efficiency of the EV battery, $P_{c, t}^{E V}$ is the rated charging power, $T_{\text {Target }}$ is the target leaving time, $E^{E V}$ is the energy capacity of the EV battery, $S O C_{\text {Target }}^{E V}$ is the EV target SOC.

Step 2: When the EVs are aggregated, the aggregator will decide which EVs to discharge or charge. The communication process between EV, aggregator, passenger and microgrid controller is shown in Fig. 5.

Step 3: When the SOC of EV does not meet the Eq. (10), the $\mathrm{EV}$ will remove from the aggregator and directly charge to the target SOC. Then the EV will wait for its owner to return/off duty.

The aggregate charging is shiftable, when the power generation is less than the demand in airport microgrid, the aggregator will control the EVs to stop charging or even discharging. The flexibility of $\mathrm{V} 2 \mathrm{G}$ can be assessed by the maximum $\mathrm{V} 2 \mathrm{G}$ power and the aggregated battery energy.

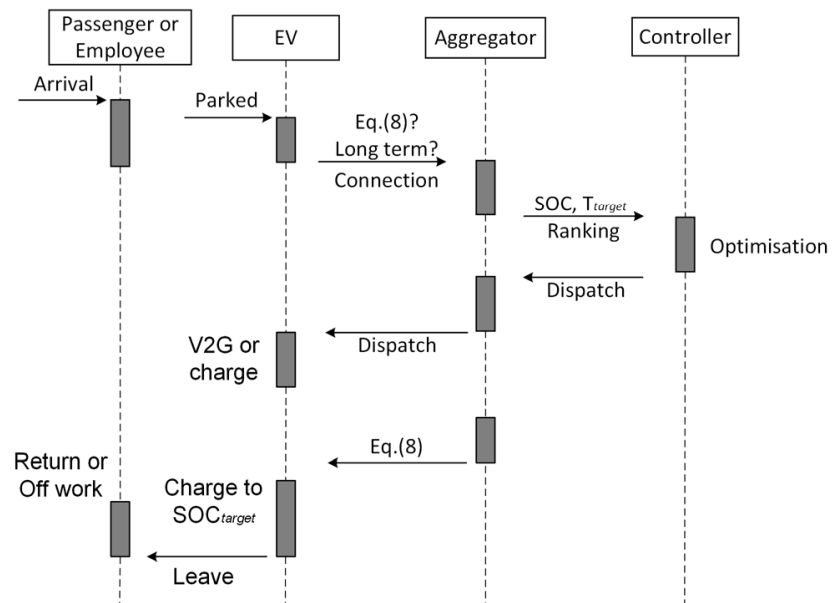

Fig. 5 Agent-based communication between EVs, aggregator, passengers and microgrid controller.

\subsection{Demand response agent}

The demand response agent contains three aggregators: EV long-term parking aggregator, EV short-term parking aggregator, and ESS. The objective of these agents' control strategy is to achieve resilience of the microgrid by reducing the imported power from the main grid.

$$
P_{N e e d, t}=P_{P V, t}+P_{W T, t}-\left(P_{E A, t}+P_{E V, t}^{C}+P_{T B, t}\right)
$$

Where the $P_{\text {Need,t }}$ is the power required to achieve power balance, $P_{E V, t}^{C}$ is the controlled $\mathrm{EV}$ charging power, $P_{T B, t}$ is the terminal building power load.

The control logic is "EVs priority", i.e., when the microgrid has excessive power, the EVs get charged prior to the ESS; When the microgrid requires power, the ESS is discharged before EVs. This will ensure the EVs have sufficient power reserve and SoC to service the passengers. Within the EV aggregator, the number of dispatched charging/discharging EVs depends on how much power is required from the 
microgrid, and the EVs are selected from the ranking list by prioritising target leaving time. As shown in Fig. 6.

$$
P_{E S, t}^{D P}=\left\{\begin{array}{cl}
P_{\text {Need }, t}-P_{E V, t}^{D P} & , P_{\text {Need }, t}>0 \\
0 & , P_{\text {Need }, t}=0 \\
\min \left(P_{\text {Max }}^{E S}, P_{\text {Need }, t}\right) & , P_{\text {Need }, t}<0
\end{array}\right.
$$

Where, $P_{E S, t}^{D P}$ and $P_{E V, t}^{D P}$ are the dispatched charging/discharging power of the ESS and EV respectively.

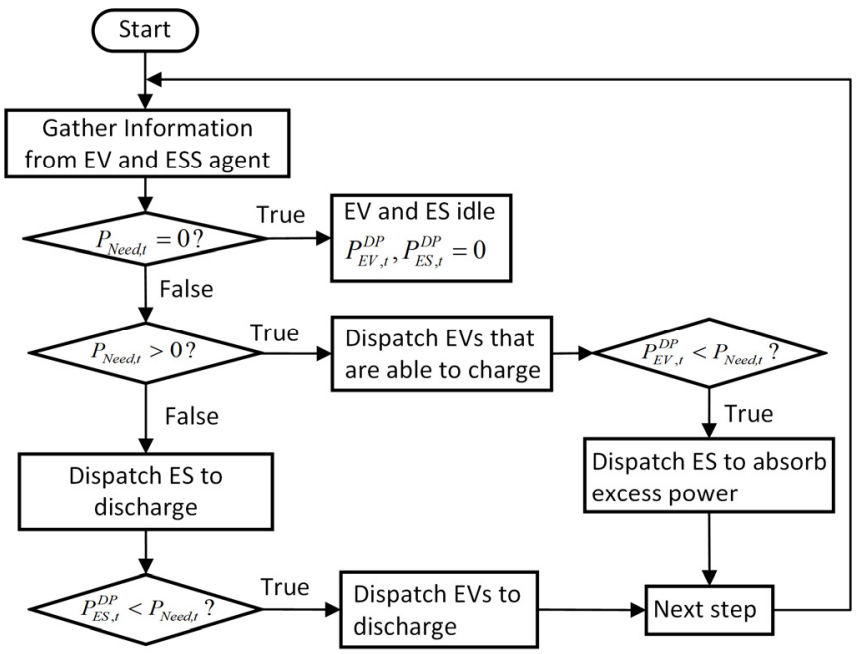

Fig. 6 Coordinated control of demand response agent

\subsection{Airport energy demand}

There are various types of conventional electric loads in the airport terminal buildings. Because of the lack of real terminal building energy consumption data and the load modelling is not the main focus of this work, the equivalent load pattern model is used instead of detailed modelling on airport energy demand. There are several general features of energy behaviour in the Medium size airport, based on the data metered in [13]. Based on the energy patterns of the airport terminal building, there are seven load periods during a typical day in an airport: night load, morning start-up, morning ramp-up, peak load, stabilised load, evening setback, and evening shut-down. The peak load appears when the passengers and employees are arriving at the airport in the morning. The electric load and EA charging load, which has been modelled in 3.3, are the primary energy consumption loads in airport microgrid, as shown in Fig. 7.

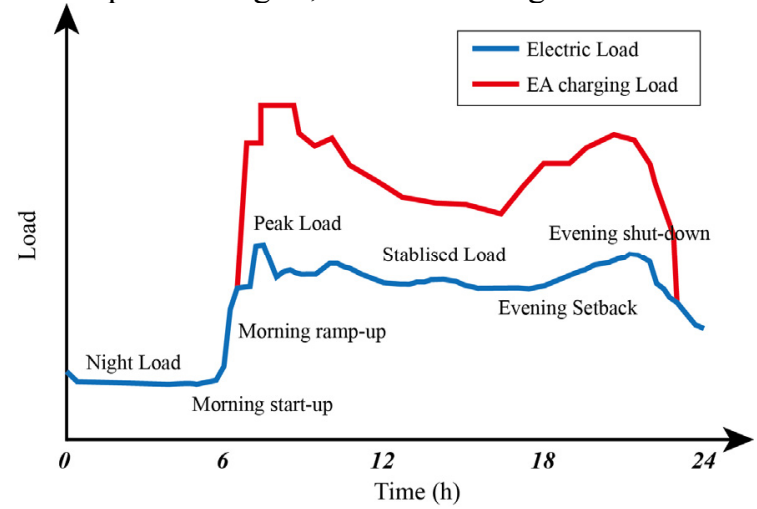

Fig. 7 Airport electric load and EA charging load

\subsection{Microgrid operation indices}

Several operation indices are utilised to assess the operation resilience of the microgrid, including maximum load on the busbar, peak to average ratio (PAR), loss of load probability (LOLP), and renewable generation self-consumption rate (RGSR). The peak to average ratio (PAR) is calculated as Eq. (1), other indices are calculated as Eq. (13) - (16).

Maximum load on the busbar:

$$
P_{l, \max }=\operatorname{Max}\left(\sum_{t=1}^{T} P_{\text {load }, t}\right)
$$

Loss of Load Probability (LOLP):

$$
\begin{gathered}
L O L P=\frac{\sum_{t=1}^{T} \operatorname{hours}\left(P_{\text {load }, t}>P_{\text {gen }, t}\right)}{T} \\
\left\{\begin{array}{l}
P_{\text {load }, t}=P_{W T, t}+P_{P V, t}+P_{V 2 G, t}+P_{B 2 G, t} \\
P_{\text {gen }, t}=P_{G 2 V, t}+P_{G 2 B, t}+P_{G 2 A, t}+P_{T B, t}
\end{array}\right.
\end{gathered}
$$

Renewable generation self-consumption rate (RGSR):

$$
R G S R=\frac{\sum_{t=1}^{T}\left(P_{P V 2 m g, t}+P_{W T 2 m g, t}\right)}{\sum_{t=1}^{T}\left(P_{P V, t}+P_{W T, t}\right)}
$$

Where, $P_{P V 2 m g, t}$ and $P_{W T 2 m g, t}$ are the PV and wind generation consumed by the microgrid.

\section{Results}

Based on a previously defined airport microgrid energy system, a case study is conducted on the East Midlands Airport (IATA code: EMA). The domestic flight schedules from $29^{\text {th }}$ July to $31^{\text {st }}$ August 2019 are utilised for reformulation of the EA flight schedule and air passengers' arrival profile. Ten wind turbines and $8 \mathrm{MW}$ PV panels are used for renewable power generation. Energy storage system is sized with a $15 \mathrm{MWh}$ capacity and $5 \mathrm{MW}$ power output. The peak demand of airport terminal building load is assumed to be $2 \mathrm{MW}$. The agent-based simulation framework developed in this paper is based on the Java Agent Development (JADE) platform.

\subsection{Airport EVs scheduling and V2G service}

Different from parking lots in a residential area, the drivers who parked EVs at the airport are aggregated predominantly during the daytime. This behaviour enables the dispatchable EV aggregator resource from long-term and short-term passenger parking EVs and employee parking EVs, respectively. As shown in Fig. 8, the employee parking EVs are more regulated in the daytime while the passengers parking EVs are more stochastic. This result is linked to the airport V2G capability in terms of stored energy in the EV aggregators. Fig. 9 and Fig. 10 show the stored energy of parking lot EVs and ESS. The Energy stored in the airport parking lot EVs can reach around 8-12 MWh during the daytime when airport employees and passengers both park 
EVs at the airport. Most of the available energy is from the employee EVs and this amount of energy is stable due to the more regular staff behaviours than air passengers. The energy from short-term parking EVs ( 1 to $4 \mathrm{MWh}$ ) is larger than that of long-term ones (around 1 to $2 \mathrm{MWh}$ ). However, the basic fluctuation is caused by the short-term parkin EVs while the long-term parking EVs can provide more stable energy over a long period of one month.

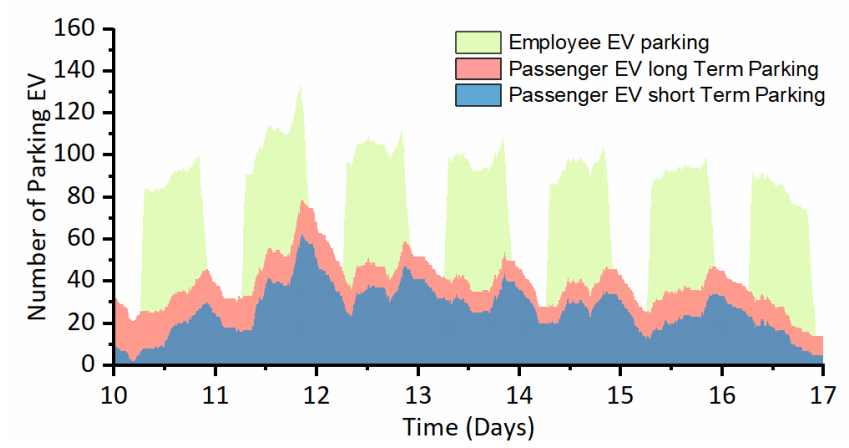

Fig. 8 Airport parking EVs occupancy and aggregation from day 10 to 17

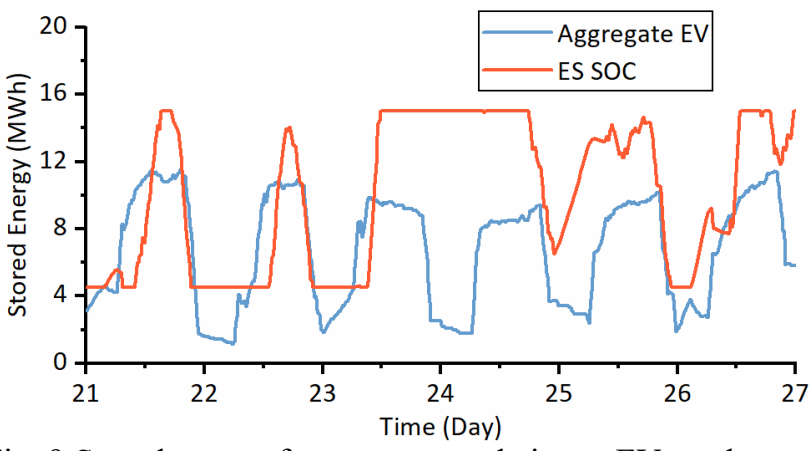

Fig. 9 Stored energy from aggregated airport EVs and energy storage system from day 21 to 27 for one week

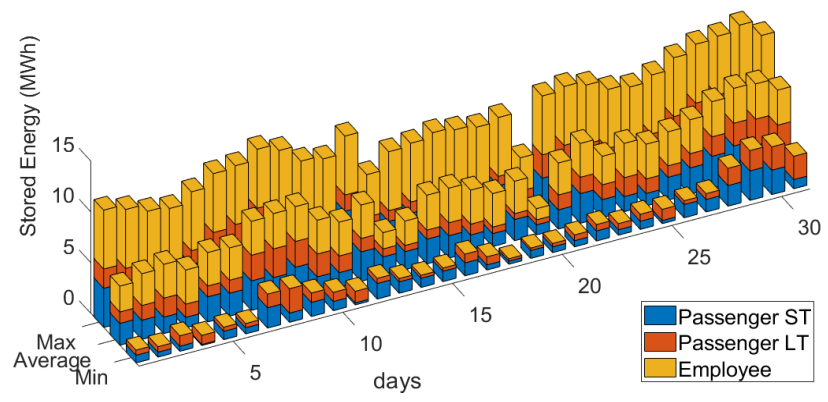

Fig. 10 Daily maximum, average, and minimum stored energy in EVs belong to short-term (ST), long-term (LT) parking passengers and employees for one month

\subsection{Microgrid energy management solution with operation assessment}

Fig. 11 shows the airport microgrid energy management solutions. The majority of airport loads including the charging of EVs and EA are supplied by the renewable power generation. But due to the uncertainties of the PV and wind generation, sometimes the microgrid has to drag the power from the main grid. When the EA charging load exceeds the microgrid generation, the ESS and V2G (EV discharging) can support the system to achieve power balance by reducing the energy requirements from the main grid, hence improve the resilience of the airport microgrid. The parking lot EVs will absorb the exceeded PV generation when the ESS is full, and these EVs will discharge to the microgrid through the designed $\mathrm{V} 2 \mathrm{G}$ agents when the evening peak load occurs from 20:00 to 21:00. The results also show that the parking lot EVs can help to absorb the surplus renewable power generation and support the microgrid power balance. The parking lot EVs can serve as an alternative stable energy storage during the daytime.

Two cases are conducted to prove the benefits of $\mathrm{V} 2 \mathrm{G}$ from the parking lot EVs: Case 1, EVs are only controlled to absorb the excessive generation without V2G; Case 2, EVs are controlled with V2G strategy.

Table 2 Microgrid assessment indices

$$
P_{l, \max , t} \quad P A R \quad L O L P \quad R G S R
$$

\begin{tabular}{lcccc}
\hline $\begin{array}{l}\text { Case 1 } \\
\text { (without V2G) }\end{array}$ & $11.46 \mathrm{MW}$ & 4.00 & $40.74 \%$ & $54.19 \%$ \\
$\begin{array}{l}\text { Case 2 } \\
\text { (with V2G) }\end{array}$ & $11.24 \mathrm{MW}$ & 3.85 & $9.28 \%$ & $56.19 \%$ \\
\hline
\end{tabular}

The microgrid assessment indices are shown in Table 2. In Case 1, the maximum load of the microgrid can reach 11.24 MW and the $P A R$ is 3.85 , indicating that the energy consumption of the microgrid has a large fluctuation during a day. This is mainly caused by the EA charging demand. These two figures are reduced in Case 2 to $11.46 \mathrm{MW}$ and 3.85 , respectively. This proves that the V2G strategy can help to reduce the difference between peak and valley of the load. The LOLP of Case 1 is as low as $9.28 \%$ of operation time when the load cannot be met by microgrid generation. Comparing with the Case 2, the possibility of generation and demand mismatch under the uncertainty of DERs is reduced sharply from $40.74 \%$ to $9.28 \%$. This proves that the airport microgrid energy management solution has the ability to achieve the resilience through V2G and ESS. This also indicates that a large proportion of the energy consumed in the microgrid is provided by renewable power generation. The RGSR is an index that can help determine whether the installed generation capacity is too high or too low. Due to the fluctuation of renewable generation associated with airport energy demand, a large amount of renewable power generation is exported to the grid. This indicates that the installed capacity of the ESS should be increased to absorb the surplus renewable power generation. 


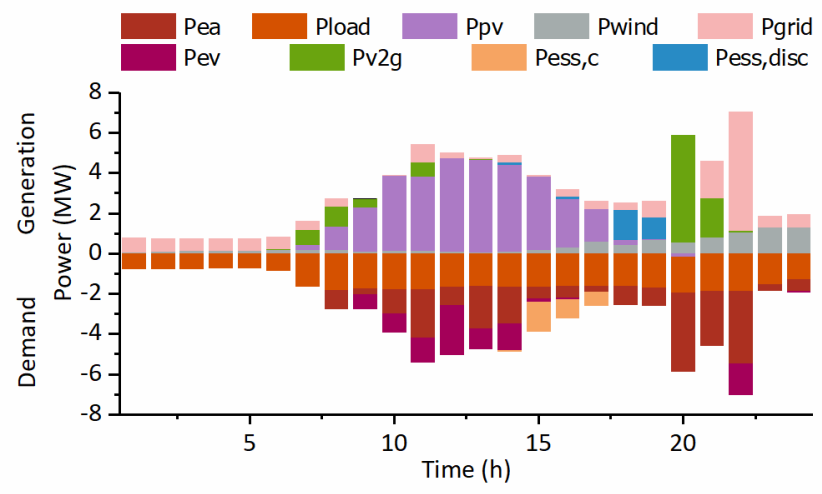

(a) Working day

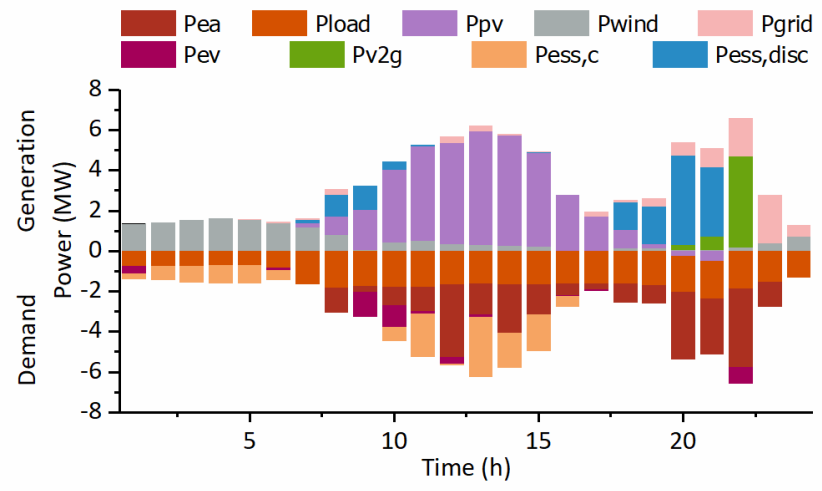

(b) Weekend

Fig. 11 Microgrid energy management solutions on typical days

\section{Conclusion}

The multi-agent based airport microgrid energy management solution is able to meet the stochastic electric aircraft charging requirement. The new airport microgrid can utilise the airport parking EVs to provide V2G by linking with flight schedule. The proposed microgrid energy management solution can improve the microgrid resilience and reduce the loss of load probability. This can be useful to planners and operators of airport microgrid systems. To achieve electrified air transport, the interaction between EVs and EA will generate new V2G flexibility to the airport microgrid as well as the main power grid. Furthermore, the microgrid is able to achieve resilient operation with high penetration of renewable power generation and high-power EA charging. In future research, the fundamental energy coupling between airport EVs and EA will be further investigated based on the air transport modelling, and socio-economic preferences of airport parking EV drivers will be considered. A complete techno-economic-environment assessment of the airport microgrid system will be conducted.

\section{Acknowledgements}

This work has been funded by EPSRC Supergen Energy Networks Hub (grant number: EP/S00078X/1), and UK
Department for Transport Technology Research Innovation Grants (T-TRIG2020).

\section{References}

[1] A. R. Gnadt, R. L. Speth, J. S. Sabnis, and S. R. H. Barrett, 'Technical and environmental assessment of allelectric 180-passenger commercial aircraft', Prog. Aerosp. Sci., 2019, 105, pp. 1-30

[2] B. P. J. Ansell and K. S. Haran, 'Electrified Airplanes', IEEE Electrif. Mag., 2020, 8, (2), pp. 18-26

[3] B. J. Brelje and J. R. R. A. Martins, 'Electric, hybrid, and turboelectric fixed-wing aircraft: A review of concepts, models, and design approaches', Prog. Aerosp. Sci., 2019, 104, pp. 1-19

[4] M. Schmidt, A. Paul, M. Cole, and K. O. Ploetner, 'Challenges for ground operations arising from aircraft concepts using alternative energy', J. Air Transp. Manag., 56, 2016

[5] M. Maigha and M. L. Crow, 'A Transactive Operating Model for Smart Airport Parking Lots', IEEE Power Energy Technol. Syst. J., 2018, 5, (4), pp. 157-166

[6] Y. Xiang, H. Cai, J. Liu, and X. Zhang, 'Technoeconomic design of energy systems for airport electrification: A hydrogen-solar-storage integrated microgrid solution', Appl. Energy, 2021, 283, p. 116374

[7] 'Alice | Eviation', https://www.eviation.co/alice/, accessed 21 September 2020

[8] Richard de Neufville: 'Airport systems planning, design, and management' (Air Transport Management, 2013)

[9] S. Ison, I. Humphreys, and T. Rye, 'UK airport employee car parking: The role of a charge?', J. Air Transp. Manag., 2007, 13, (3), pp. 163-165

[10] M. K. Deshmukh and S. S. Deshmukh, 'Modeling of hybrid renewable energy systems', Renew. Sustain. Energy Rev., 2008, 12, (1), pp. 235-249

[11] ICAO, 'Renewable Energy for Aviation: Practical Applications To Achieve Carbon Reductions and Cost Savings' (ICAO, 2017).

[12] 'Enercon', https://www.enercon.de/home/, accessed 13 June 2021

[13] S. Ortega Alba and M. Manana, 'Characterization and analysis of energy demand patterns in airports', Energies, 2017, 10, (1), pp. 1-35 